\title{
Characterization of kinesiological patterns of the frontal kick, mae-geri, in karate experts and non-karate practitioners
}

António M. VENCESBRIT01, 4*, Marco A. Colaço BRANC01 ${ }^{1}$, Renato M Cordeiro FERNANDES1, Mário A. Rodrigues FERREIRA ${ }^{1}$, Orlando J. S. M. FERNANDES ${ }^{2}$, Abel A. Abreu FIGUEIREDO ${ }^{3}$, 4, \& Gonçalo BRANCO ${ }^{1}$

${ }^{1}$ Sports Sciences School of Rio Maior, Polytechnic Institute of Santarém, Rio Maior (Portugal)

${ }^{2}$ Sport and Health Department, Évora University (Portugal)

${ }^{3}$ Polytechnique Institute of Viseu (Portugal)

${ }^{4}$ International Martial Arts and Combat Sports Scientific Society - IMACSSS (Poland)

Recepción: 18/11/2013; Aceptación: 11/03/2014; Publicación: 26/03/2014.

\begin{abstract}
Presently, coaches and researchers need to have a better comprehension of the kinesiological parameters that should be an important tool to support teaching methodologies and to improve skills performance in sports. The aim of this study was to (i) identify the kinematic and neuromuscular control patterns of the front kick (mae-geri) to a fixed target performed by 14 experienced karate practitioners, and (ii) compare it with the execution of 16 participants without any karate experience, allowing the use of those references in the analysis of the training and learning process. Results showed that the kinematic and neuromuscular activity during the kick performance occurs within 600 ms. Muscle activity and kinematic analysis demonstrated a sequence of activation bracing a proximal-to-distal direction, with the muscles presenting two distinct periods of activity $(1,2)$, where the karateka group has a greater intensity of activation - root mean square (RMS) and electromyography (EMG) peak - in the first period on Rectus Femoris (RF1) and Vastus Lateralis (VL1) and a lower duration of co-contraction in both periods on Rectus Femoris-Biceps Femoris and Vastus Lateralis-Biceps Femoris (RF-BF; VL-BF). In the skill performance, the hip flexion, the knee extension and the ankle plantar flexion movements were executed with smaller difference in the range of action (ROA) in the karateka group, reflecting different positions of the segments. In conclusion, it was observed a general kinesiological pattern, which was similar in karateka and non-karateka practitioners. However, in the karateka group, the training induces a specialization in the muscle activity reflected in EMG and kinematic data, which leads to a better ballistic performance in the execution of the mae-geri kick, associated with a maximum speed of the distal segments, reached closer to the impact moment, possibly representing more power in the contact.
\end{abstract}

Palabras clave: Kinesiology; electromyography; motor control; martial arts; combat sports.

\section{Caracterización de los patrones cinesiológicos de la patada frontal, mae-geri, en practicantes expertos de kárate y en sujetos no practicantes Resumen}

Actualmente, los entrenadores e investigadores necesitan comprender bien los parámetros cinesiológicos del movimiento ya que son una herramienta importante de soporte de las metodologías de entrenamiento y enseñanza, y para mejorar el rendimiento de los gestos motores. El objetivo de este estudio fue (i) identificar los patrones cinemáticos y del control neuromuscular de ejecución de la patada frontal (mae-geri) en un objetivo fijo, realizada por 14 karatecas cinturón negro, (ii) y comparar con la ejecución del mismo gesto técnico realizada por 16 participantes sin práctica o experiencia en kárate, siendo posible el uso de esos datos en análisis
Caracterização dos padrões cinesiológicos do pontapé frontal, mae-geri, em karatecas expertos e indivíduos não praticantes

\section{Resumo}

Actualmente, treinadores e investigadores necessitam de compreender bem os parâmetros cinesiológicos do movimento porque são uma ferramenta importante de suporte das metodologias de treino e ensino, e para melhorar a performance dos gestos motores. 0 objective deste estudo foi (i) identificar os padrões cinemáticos e de controlo neuromuscular da execução do pontapé frontal (mae-geri) num alvo fixo e realizado por 14 karatecas cinto negro, (ii) e comparar com a execução do mesmo gesto técnico realizada por 16 participantes sem qualquer prática ou experiência de karate, tornando possível o uso desses dados na analise do treino e do

*Email: abrito@esdrm.ipsantarem.pt. Address: Escola Superior de Desporto de Rio Maior. Av. Dr. Mário Soares. 2040-326. Rio Maior (Portugal). 
del entrenamiento y del proceso de aprendizaje del kárate. Se verificó que la actividad cinemática y neuromuscular de ejecución de esta patada sucede en un espacio temporal de $600 \mathrm{~ms}$. La actividad muscular y cinemática evidencia la existencia de una norma secuencial temporal de intervención segmentar con un sentido próximo-distal, donde los músculos estudiados tienen dos momentos distintos de actividad (períodos 1 , 2). En el análisis electromiográfico (EMG), el grupo de karatekas presenta una mayor intensidad de activación (root mean square - RMS) y de pico de actividad en el músculo Rectus Femoris (RF1) y Vastus Lateralis (VL1), y menor tiempo de contracción en ambos períodos en las relaciones entre los músculos Rectus Femoris-Biceps Femoris e Vastus Lateralis-Biceps Femoris. En la realización de esta acción motora, los movimientos segmentares de flexión de muslo, de extensión de la pierna y de flexión plantar del tobillo fueron realizados con menor amplitud angular (range of action - ROA) por los karatekas, reflejando diferentes posicionamientos de los segmentos entre grupos. En conclusión, existe un patrón cinesiológico general, semejante entre practicantes y no practicantes de kárate. En el grupo de karatecas el entrenamiento induce una especialización de la actividad muscular, reflejada en los resultados del EMG y de la cinemática de movimiento, produciendo una mejor acción balística en la ejecución del mae-geri, que en asociación con una velocidad máxima de los segmentos distales, alcanzada cerca del momento del impacto, puede traducirse en un impacto más potente.

Keywords: Cinesiología; electromiografía; control motor; artes marciales; deportes de combate. processo de aprendizagem do karate. Verificou-se que a actividade cinemática e neuromuscular na execução deste pontapé acontece num espaço temporal de $600 \mathrm{~ms}$. A actividade muscular e cinemática evidencia a existência de um padrão sequencial temporal de intervenção segmentar com um sentido próximo-distal, onde os músculos estudados têm dois distintos momentos de actividade (períodos 1,2). Na análise electromiografia (EMG), o grupo de karatecas apresenta uma maior intensidade de activação (rootmeansquare- RMS) e de pico de actividade no musculo Rectus Femoris (RF1) eVastus Lateralis (VL1), e menor tempo de cocontração em ambos os períodos nas relações entre os músculos Rectus Femoris - Biceps Femoris e Vastus Lateralis - Biceps Femoris. Na realização desta acção motora, os movimentos segmentares de flexão da coxa, de extensão da perna e de flexão plantar do tornozelo foram realizados com menor amplitude angular (range of action - ROA) pelos karatecas, reflectindo diferentes posicionamentos dos segmentos entre grupos. Em conclusão, existe um padrão cinesiológico geral, semelhante entre praticantes de karate e não praticantes de karate. Todavia, no grupo de karatecas o treino induz uma especialização da actividade muscular, reflectida pelos resultados do EMG e da cinemática do movimento, o que conduz a uma melhor acção balística na execução do mae-geri, em associação com um máximo de velocidade dos segmentos distais, alcançado próximo do instante do impacto, o que poderá traduzir-se num impacto mais potente.

Palavras-chave: Cinesiologia; electromiografia; controlo motor; artes marciais; desportos de combate.

\section{1.- Introduction}

Karate is a martial art and combat sport present on the Combat Games developed by Sportaccord, and a recognized sport by the International Olympic Committee, demonstrating its actual worldwide dimension of competitive format. This specialized format is linked with other sport practices purposes, such as recreational, fitness and self-defence ones.

The body movements of fighting in this sport include striking techniques delivered with special parts of the body to specific body targets. These actions must be performed in a fast, accurate and powerful manner, respecting rules such as the sundome rule in karate. Kicking techniques are basic to perform this sport and one of them is the mae-geri, the front kick.

The mae-geri is executed as a ballistic action when trying to reach an opponent's body target with the foot, performed as fast as possible, mainly in competition, where a short duration of the movement can impose serious limitations to proprioceptive and visual correction. Its performance requires a dynamic joint action sequence with the participation of the torso, pelvis, knee, ankle and foot, allowing the use of energy that flows from the hip to the foot, resulting from muscle contraction in a reciprocal innervation process (Nakazawa, 1999).

In this proximal-to-distal sequence, the timing of the lower limb movements around the transverse axis, such as thigh flexion, leg extension and ankle plantar flexion, is not clear. Besides empirical approaches (Link \& Chou, 2011; Nakazawa, 1999), the literature on this topic is very scarce in providing clear evidence on the kinematic and electromyography (EMG) characterization of the mae-geri or in confirming the empirical knowledge.

The execution of new sport skills, which are different from the everyday life skills, creates new demands, both in the central motor control system and to the peripheral one. Therefore, the kinematic and muscle activity must be controlled in order to respond adequately to these new demands, and to improve the skill execution until proper adaptation is attained. 
Some assessments in sport skills, identifies a segmental sequence on motor tasks of the upper limb or lower limb, and have indicated a proximal-to-distal sequence, including, for example, joint angular velocities or endpoint linear speeds (VencesBrito, 2012; VencesBrito, Rodrigues, Cortes, Fernandes \& Pezarat-Correia, 2011), or onset time of muscles recruitment and time of peak of activity (Sørensen, Zacho, Simonsen, Dyhre-Poulsen \& Klausen, 1996; VencesBrito, 2012; VencesBrito et al., 2011). However, in these complex movements, such as kicking a specific target, the knowledge and understanding of the task must be achieved, and it should be possible to learn it better, so as to increase the performance of the practitioners.

In the study of the lower limb movements in taekwondo, Sørensen et al. (1996) with the support of EMG data, found a relationship between acceleration and deceleration of the segments and the muscle activity, concluding that lower leg acceleration was caused partly by a knee extensor muscle moment and partly by a motion-dependent moment arising from the thigh angular velocity.

In karate, the few studies available in the literature on the frontal kick are focused on repeatability, in the kinetic and kinematic structure of the lower limb task or in the neuromuscular control activity in national and international athletes (Pozo, Bastien, \& Dierick, 2011; Sbriccoli et al., 2010; Sforza et al., 2002), suggesting that those indicators can be used in the athletes selection.

Other studies are related to the neuromuscular activation strategy in the lower limb segments, but in the round house kick, performed with impact or without impact (Quinzi, Camomilla, Felici, Di Mario \& Sbriccoli, 2013), where was found improvements in the conduction velocity and muscle fibbers recruitment in elite karateka, which, according to the authors, may be associated with the training. Specifically, in mixed martial arts elite fighters, McGill, Chaimberg, Frost \& Fenwick (2010) described a double peak of muscle activity during the performance of a variety of strokes. The initial peak was probably related to enhance stiffness and stability, then a brief relaxation phase of some muscles as the speed of limb increase, and a second peak to create linkage stiffness and very high strike force. This contract-relax-contract pulsing cycle suggests also the importance of the rate of muscle relaxation during training in order to optimize the speed and force of the strike.

A powerful karate technique such the mae-geri depends, partially, on the coordinated momentum of several parts of the body. This is supported by a strong muscular contraction to produce a maximum speed to the distal extremity during the time of contact with the target. However, at the same time, it could be acting in a dysfunctional way, which may lead to the emergence of injuries.

The muscle activation pattern during a motor skill execution, registered on an EMG recording, allows the measurement and characterization of the muscular activity, including the inter-muscular coordination patterns (Basmajian \& De Luca, 1985), and in association with the data collected from the video images of the skill execution, allows explanation of the kinematic and EMG patterns on experienced athletes.

Thus, the general purpose of this study was to provide a better comprehension of the kinesiological parameters that should be an important tool to support coaches (Sensei's) teaching methodologies, which may be done by studying the training effects, comparing expert athletes and non-practitioners, as shown by VencesBrito et al. (2011) with superior limb punch skills. This, in turn, leads to a better performance, avoiding teaching and learning mistakes and preventing possible injuries that occur during practice or competition (Macan, Bundalo-Vrbanac \& Romic, 2006; Pappas, 2007; Pieter, 2010; Zetaruk, Violan, Zurakowski \& Micheli, 2005).

To achieve the general purpose, this study will (i) make a kinesiological characterization of the patterns of the front kick, mae-geri, performed by experienced karateka, and (ii) compare the kinematic and EMG patterns of the mae-geri between experienced karateka and a control group (with no karate experience). We hypothesize that there will be differences in the kinematic and EMG patterns between karateka and non-karateka, expecting that the movement time of each lower limb segment will be performed quickly and with a higher muscle activity in less time by karateka. It is expected that maximum speed in the distal segments is reached closer to the impact moment by karateka than by non-karateka. 


\section{2.- Method}

\section{1.-Participants}

Two groups of male aged between 18 and 35 years old participated in the study: one composed with 14 karate practitioners $(K), 2^{\text {nd }}$ Dan black belts with a mean practice of 13 years, and a control group with 16 students of sports sciences without previous karate experience (NK). All participants were informed and signed a consent document, approved by the scientific committee of the Sports Sciences School of Rio Maior - Polytechnic Institute of Santarém (Portugal). The characterization of the two groups is shown in Table 1.

Table 1. Physical characterization of the participants

\begin{tabular}{lcc}
\hline & Karate group & Non karate \\
\hline Age (years) & $24 \pm 7$ & $23 \pm 6$ \\
Height $(\mathrm{cm})$ & $171 \pm 7$ a & $179 \pm 6$ a \\
Weight $(\mathrm{kg})$ & $72 \pm 19$ & $73 \pm 10$ \\
Leg length $(\mathrm{cm})$ & $89 \pm 6$ & $90 \pm 5$ \\
Body fat $(\%)$ & $17 \pm 7$ & $15 \pm 4$ \\
\hline Values are means \pm SD. a Indicates & statistically \\
significant differences were found between groups \\
(p $\leq .05)$.
\end{tabular}

\section{2.- Experimental design}

The study focussed on the kinematic and electromyographic analysis of karate frontal kick movement, mae-geri, targeted to an area at a height of $90 \mathrm{~cm}$ from the ground, located in a vertical floor training bag.

Each subject performed, with the right lower limb (dominant), three fast and strong repetitions of the mae-geri kick, starting from the karate typical stance of zenkutsu dachi, and ending when the foot makes contact with the target area of the bag with the lower part of the metatarsals - koshi (see Fig. 1). The median value of the three trials was used for analysis.

The task started at a sound signal synchronized with a trigger, and ended at impact defined by the first video frame where the koshi contacted the bag. This instant was defined as zero time to all data analysis. All kinematics and electromyographic measurements were synchronized.

Figure 1. Illustration of the experimental setup showing the subject facing the bag at the starting position of zenkutsu dachi, with the right lower limb in backward extension, and the left lower limb flexed on the thigh and leg, with the foot on the floor pointing forward, and the movement until the final position of the foot in contact with the target.

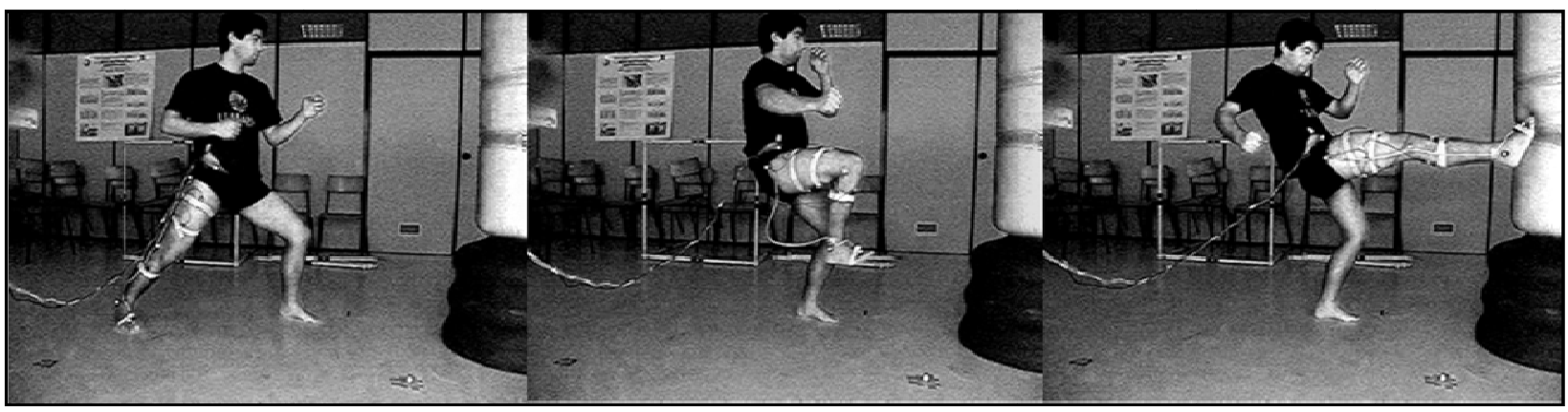

\section{3.- Apparatus}

To identify the right lower limb segments during the execution movement, five reflective markers were placed on the right lower limb, specifically on the right anterior superior iliac spine (RASIS), the prominence of the greater trochanter external surface, the lateral epicondyle of the 
femur, the distal apex of the lateral malleolus and the dorsal aspect of the second metatarsal head (Santos-Rocha, Veloso, Valamatos, Machado \& Andre, 2009).

Kinematic data were collected with a sampling frequency of $210 \mathrm{~Hz}$ by a high speed camera (Casio EX-FH20). The camera was positioned at a distance of two meters, perpendicular to the plane of movement. The videos were initially cut and analyzed with resource to the modules Trimmer, Digitize, Transform, Filter and Display, respectively, of the software Ariel Performance Analysis System (APAS, Ariel Dynamics-2003). The initial criterion for cutting the video sequence to analyze was $200 \mathrm{~ms}$ before the trigger and the final criterion was $300 \mathrm{~ms}$ after the contact with the bag. Spatial references were introduced according to the APAS recommendations for 2D analysis.

The surface electromyographic muscle activity (EMG) was recorded through the MP100 Data Acquisition System with active bipolar surface electrodes (centers separated by $20 \mathrm{~mm}$ ), TSD Model 150TM (BIOPAC Systems, Santa Barbara, CA, USA).

After skin preparation, electrodes were placed in agreement with the rules proposed by the European SENIAM project (Hermens et al., 2000), with the ground electrode on the fifth lumbar vertebra. The EMG record was collected, at a sampling rate of $1050 \mathrm{~Hz}$. The EMG signal processing was performed with software developed in MATLAB® (The Mathworks Inc, Natick Massachusetts, USA).

\section{4.- Data reduction}

\section{Kinematic}

In the Digitize module of the APAS system, the virtual lab space was calibrated using eight control points, which were identified by a number and respective coordinates ( $\mathrm{x}, \mathrm{y})$, in order for the coordinates of the reflective markers fixed on the participants to be computed by auto-digitized process. Once the markers were identified in all the frames, the reconstruction of the trajectory was made with the transform module, using the Direct Linear Transformation-DLT. These paths were then smoothed, using a low pass digital filter with a $5 \mathrm{~Hz}$ cut off (Winter, 2009) in the filter module of the APAS software (see Fig. 2).

The dependent Kinematic variables of hip, knee and ankle forward movements consisted in: time of beginning and end of movement, joint angles and angle range of motion (ROM - difference between maximum and minimum angular positions of the joints obtained during the movements), the range of action (ROA - difference between initial and contact angular position), linear speed peaks and their time of occurrence. The joint angles and linear velocity were computed through the APAS system and the Matlab routine, respectively.

$E M G$

Surface EMG was recorded from Quadriceps Femoris in the portions of the Rectus Femoris (RF) and Vastus Lateralis (VL), the long head of the Biceps Femoris (BF) muscle, the Tibialis Anterior (TA) muscle, and from the external portion of the Gastrocnemius (GA).

They were digitally filtered, full wave rectified and smoothed with a low pass filter of $12 \mathrm{~Hz}$ (Butterworth, $4^{\text {th }}$ order), normalized, with reference to the average value of the maximum peak of electromyographic activity of the three runs in each studied muscle (see Fig. 2). This procedure allows a more correct use of the EMG activity during dynamic action (Ball \& Scurr, 2011; Konrad, 2005).

To access time and amplitude parameters of the EMG bursts, they were isolated on each trial. All the muscles studied showed two different activations, separated by an electrical silence visible in the processed EMG, during the mae-geri performance and referenced as first (1) and second (2) activation periods.

The dependent variables studied were the onset and offset of the muscles activation time, time of the peak, peak of activity and EMG root mean square (RMS) between onset and offset and the co-contraction time between muscles. 
The determination of the onset/offset on the movements and muscle activation was visually performed on the Matlab output, by a single expert researcher, and the further data were performed by the Matlab software (Micera, Vannozzi, Sabatini \& Dario, 2001).

Figure 2. Illustration of the hip, knee and ankle curves of the movements in the lower limb segments, in degree, and the two activations on the EMG of the RF rectus femoris, VL vastus lateralis, BF biceps femoris, TA

tibialis anterior and GA gastrocnemious muscles in the mae-geri performance by a karate practitioner.

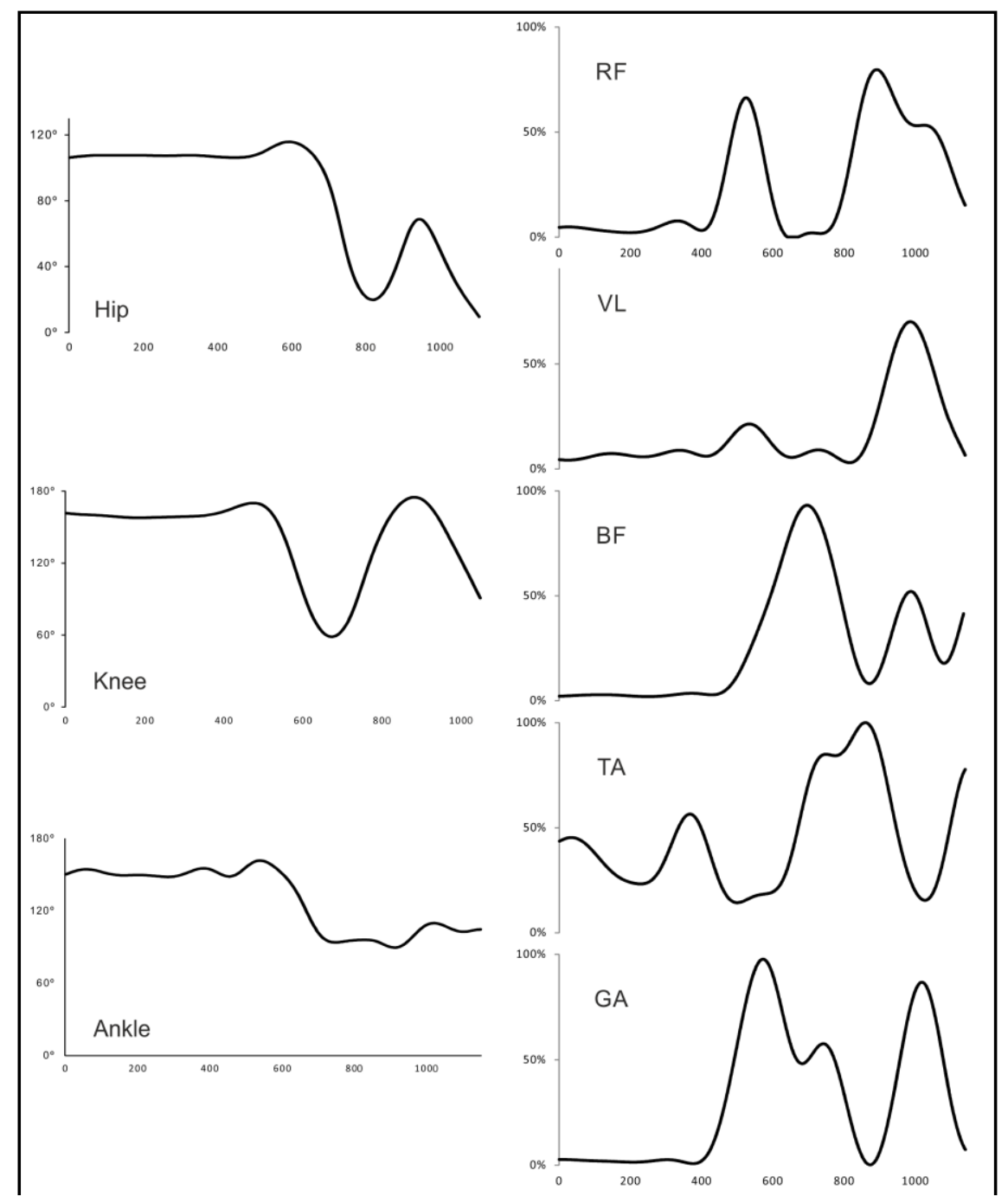

\section{5.- Statistics}

To analyze the differences between the two groups for the kinematic and EMG variables, the normality of the distribution (Shapiro-Wilks test) and the homogeneity of variances (Levene's test) was tested and assumed, in the inferential data analysis of variance with the OneWay ANOVA technique, using the software program "Statistical Package for the Social Sciences" (SPSS 20.0 for Windows ${ }^{\circledR}$, SPSS Inc, Chicago, USA). For all cases, the level of statistical significance was set at $\mathrm{p}$ $\leq 0.05$.

\section{3.- Results}

\section{1.- Kinematic characterization and comparison}

As it may be observed in Table 2, that presents the dependent kinematic variables on the karate and non-karate groups, as well as the significant differences, concerning the mae-geri, the initial displacement of the segments shows a proximal-to-distal direction. Thus, the first joint to 
initiate the movement is the hip, followed by the knee and then by the ankle. This pattern is verified in both groups.

The initial angular position of the joints is similar for both groups in the hip, however, for the knee and the ankle joint, karate practitioners present a significantly lower knee extension, when compared with non-practitioners ( $\mathrm{K}=172^{\circ}$; $\left.\mathrm{NK}=178^{\circ}, p=0.009\right)$, and in the ankle plantar flexion the karateka group presents a lower angle when compared with non-practitioners $(\mathrm{K}=$ $120^{\circ}$; $\mathrm{NK}=144^{\circ}, p=0.019$ ). The final angular position remains similar in both groups, with the exception of the ankle joint, where a superior ankle plantar flexion was observed for the karateka group, when compared with the non-karateka group then the foot contacts with the training bag (K $\left.=98^{\circ} ; \mathrm{NK}=90^{\circ}, p=0.003\right)$. The ROA shows that the karateka group performs a significantly smaller angular displacement than the non-karateka group for all joints ( $\left(\mathrm{K}=61^{\circ}\right.$; $\left.\mathrm{NK}=74^{\circ}, p=0.042\right)$; $(\mathrm{K}=$ $41^{\mathrm{o}}$; $\left.\mathrm{NK}=49^{\circ}, p=0.033\right)$; ( $\mathrm{K}=23^{\circ}$; $\left.\mathrm{NK}=54^{\circ}, p=0.005\right)$, respectively for the hip, knee and ankle). This result was corroborated by the difference between maximum and minimum angular positions of the joints obtained during the movements (ROM), which also maintains smaller angular displacement for the karateka group, but with significant differences only for the ankle joint $(\mathrm{K}=$ $41^{\mathrm{o}}$; $\mathrm{NK}=64^{\circ}, p=0.013$ ).

Table 2 Average and standard deviation of the kinematic dependent variables and significant differences in the execution of mae-geri by karate (K) and non-karate participants (NK).

\begin{tabular}{|c|c|c|c|c|}
\hline & & Hip & Knee & Ankle \\
\hline \multirow{2}{*}{ Onset Time } & $\mathrm{K}$ & $500 \pm 72$ & $399 \pm 52^{a}$ & $348 \pm 33$ \\
\hline & NK & $461 \pm 57$ & $366 \pm 26$ a & $338 \pm 30$ \\
\hline \multirow{2}{*}{ Initial angle } & $\mathrm{K}$ & $130 \pm 12$ & $172 \pm 6^{a}$ & $120 \pm 19 a$ \\
\hline & NK & $128 \pm 8$ & $178 \pm 8 \mathrm{a}$ & $144 \pm 30$ a \\
\hline \multirow{2}{*}{ Contact angle } & $\mathrm{K}$ & $69 \pm 26$ & $131 \pm 8$ & $98 \pm 9 a$ \\
\hline & NK & $54 \pm 28$ & $129 \pm 8$ & $90 \pm 5^{a}$ \\
\hline \multirow{2}{*}{ Range of motion (ROA) } & $\mathrm{K}$ & $61 \pm 25^{a}$ & $41 \pm 10^{a}$ & $23 \pm 25 a$ \\
\hline & $\mathrm{NK}$ & $74 \pm 29 a$ & $49 \pm 9.2^{a}$ & $54 \pm 29 a$ \\
\hline \multirow[b]{2}{*}{ Max angle } & $\mathrm{K}$ & $133 \pm 10$ & $177 \pm 5 a$ & $128 \pm 18^{a}$ \\
\hline & $\mathrm{NK}$ & $131 \pm 8$ & $183 \pm 6^{a}$ & $150 \pm 30^{a}$ \\
\hline \multirow[b]{2}{*}{ Min angle } & $\mathrm{K}$ & $60 \pm 21$ a & $71 \pm 11$ & $87 \pm 6$ \\
\hline & NK & $44 \pm 24$ a & $76 \pm 11$ & $85 \pm 5$ \\
\hline \multirow{2}{*}{ Max/min Range angle (ROM) } & $\mathrm{K}$ & $73 \pm 21$ & $106 \pm 10$ & $41 \pm 18^{a}$ \\
\hline & NK & $86 \pm 25$ & $106 \pm 13$ & $64 \pm 28^{a}$ \\
\hline \multirow{2}{*}{ Speed peak } & $\mathrm{K}$ & $2.3 \pm 0.5$ & $5.8 \pm 0.7$ & $8.1 \pm 0.9$ \\
\hline & NK & $2.1 \pm 0.3$ & $5.3 \pm 0.8$ & $7.7 \pm 1.2$ \\
\hline \multirow{2}{*}{ Time of speed peak contact } & $\mathrm{K}$ & $173 \pm 86^{a}$ & $180 \pm 16$ & $67 \pm 21$ \\
\hline & NK & $98 \pm 101^{\mathrm{a}}$ & $180 \pm 22$ & $69 \pm 18$ \\
\hline
\end{tabular}

Angle - degree; time - millisecond; speed $-\mathrm{m} . \mathrm{s}^{-1}$. ${ }^{\mathrm{a}}$ Indicates statistically significant differences between groups $(p \leq .05)$.

Regarding speed, no differences were found between groups. However, it could be seen a tendency of the karateka group to perform a higher peak of speed, in all segments, and the point where the ankle reaches this peak was closer to the instant of contact with the bag, than in the nonkarateka group. Conversely, it was verified, for the hip joint, that the karateka group achieved the maximum speed earlier than the non-karateka group (K=173 ms; $\mathrm{NK}=98 \mathrm{~ms}, p=0.038)$.

\section{2.- EMG characterization and comparison}

Table 3 shows the EMG dependent variables of the karate and non-karate subjects, indicating the significant differences between groups, where, in both groups, the first muscle to be activated was the foot dorsal flexor (TA1), followed by the first activation of the thigh flexor, leg extensors and plantar flexor muscles (RF1, VL1, GA1). The antagonist muscle of the thigh flexion and leg extension (BF1) initiates its first activity significantly earlier in the non-karateka group when compared with the karateka group (K= $435 \mathrm{~ms}$; $\mathrm{NK}=547 \mathrm{~ms}, p=0.038)$. The muscle activity 
of the BF1 also ends significantly earlier in the non-karateka group $(\mathrm{K}=114 \mathrm{~ms}$; NK $=198 \mathrm{~ms}, p=$ 0.003), but the activity time was smaller for the karateka group. The sequential pattern was the same in the second activation in both groups, with the TA2 being the first, followed by the RF2, VL2, GA2 and BF2. In the RF2 contraction, it was observed that the offset occurs significantly later in the non-karateka group ( $\mathrm{K}=-27 \mathrm{~ms}$; $\mathrm{NK}=-41 \mathrm{~ms}, p=0.048)$, after bag contact.

Table 3. Average and standard deviation in the variables of muscle EMG in the execution of mae-geri by karate $(\mathrm{K})$ and non-karate participants (NK).

\begin{tabular}{|c|c|c|c|c|c|c|c|}
\hline & & RF1 & RF2 & VL1 & VL2 & BF1 & BF2 \\
\hline \multirow{2}{*}{$\begin{array}{l}\text { Onset muscles activation } \\
\text { time }\end{array}$} & K & $548 \pm 68$ & $271 \pm 59$ & $545 \pm 58$ & $157 \pm 31$ & $435 \pm 128^{a}$ & $110 \pm 38$ \\
\hline & NK & $566 \pm 72$ & $237 \pm 48$ & $541 \pm 70$ & $153 \pm 20$ & $547 \pm 72 a$ & $128 \pm 45$ \\
\hline \multirow{2}{*}{$\begin{array}{l}\text { Offset muscles activation } \\
\text { time }\end{array}$} & $\mathrm{K}$ & $363 \pm 59$ & $-27 \pm 33 a$ & $350 \pm 56$ & $-50 \pm 17$ & $114 \pm 72^{a}$ & $-42 \pm 27$ \\
\hline & NK & $367 \pm 74$ & $-41 \pm 21$ a & $318 \pm 67$ & $-48 \pm 13$ & $198 \pm 53^{a}$ & $-37 \pm 35$ \\
\hline \multirow{2}{*}{ Time of peak EMG } & $\mathrm{K}$ & $489 \pm 61$ & $110 \pm 45$ & $465 \pm 57$ & $63 \pm 41$ & $308 \pm 135$ & $43 \pm 46$ \\
\hline & NK & $480 \pm 77$ & $77 \pm 50$ & $447 \pm 74$ & $56 \pm 30$ & $379 \pm 68$ & $56 \pm 62$ \\
\hline \multirow{2}{*}{ EMG peak } & $\mathrm{K}$ & $52 \pm 20$ a & $83 \pm 11$ & $42 \pm 25$ & $84 \pm 8$ & $74 \pm 15$ & $63 \pm 21$ \\
\hline & $\mathrm{NK}$ & $24 \pm 6^{a}$ & $84 \pm 11$ & $27 \pm 10^{a}$ & $84 \pm 16$ & $68 \pm 20$ & $52 \pm 21$ \\
\hline \multirow{3}{*}{$\begin{array}{l}\text { EMG root mean square } \\
\text { (RMS) }\end{array}$} & $\mathrm{K}$ & $33 \pm 12^{a}$ & $50 \pm 10$ & $27 \pm 15^{a}$ & $55 \pm 6$ & $41 \pm 10$ & $41 \pm 12$ \\
\hline & $\mathrm{NK}$ & $16 \pm 2^{a}$ & $50 \pm 8$ & $18 \pm 6^{a}$ & $54 \pm 11$ & $41 \pm 12$ & $36 \pm 12$ \\
\hline & & TA1 & TA2 & GA1 & GA2 & & \\
\hline \multirow{2}{*}{$\begin{array}{l}\text { Onset muscles activation } \\
\text { time }\end{array}$} & $\mathrm{K}$ & $597 \pm 125$ & $310 \pm 83$ & $472 \pm 41$ & $117 \pm 39$ & & \\
\hline & NK & $579 \pm 94$ & $267 \pm 105$ & $449 \pm 70$ & $124 \pm 71$ & & \\
\hline \multirow{2}{*}{$\begin{array}{l}\text { Offset muscles activation } \\
\text { time }\end{array}$} & $\mathrm{K}$ & $340 \pm 128$ & $40 \pm 34$ & $173 \pm 51$ & $-59 \pm 15$ & & \\
\hline & NK & $324 \pm 115$ & $39 \pm 37$ & $204 \pm 69$ & $-45 \pm 36$ & & \\
\hline \multirow{2}{*}{ Time of peak EMG } & $\mathrm{K}$ & $470 \pm 209$ & $190 \pm 60$ & $385 \pm 43$ & $38 \pm 36$ & & \\
\hline & NK & $480 \pm 133$ & $167 \pm 75$ & $367 \pm 70$ & $54 \pm 65$ & & \\
\hline \multirow{2}{*}{ EMG peak } & $\mathrm{K}$ & $46 \pm 20$ & $81 \pm 15$ & $81 \pm 15$ & $76 \pm 15$ & & \\
\hline & $\mathrm{NK}$ & $49 \pm 16$ & $83 \pm 18$ & $78 \pm 16$ & $74 \pm 20$ & & \\
\hline \multirow{2}{*}{$\begin{array}{l}\text { EMG root mean square } \\
\text { (RMS) }\end{array}$} & $\mathrm{K}$ & $30 \pm 12$ & $54 \pm 10$ & $45 \pm 9$ & $49 \pm 9$ & & \\
\hline & NK & $29 \pm 8$ & $54 \pm 9$ & $49 \pm 8$ & $49 \pm 14$ & & \\
\hline
\end{tabular}

Time - millisecond; EMG peak and RMS - \% of normalization; RF - Rectus Femoris; VL - Vastus Lateralis; BF Biceps Femoris; TA - Tibialis Anterior; GA - Gastrocnemius. a Indicates statistically significant differences between groups $(p \leq .05)$.

Regarding the peak of activity, it was reached around $489-308$ ms before the contact, in the first muscles activated (TA1, RF1, VL1) and its antagonists (GA1, BF1), for both groups. The RF1 was the first and the BF1 was the last to reach the peak.

During this activation period, the intensity peak was around $24-52 \%$ of maximum activity in the agonists TA1, RF1, VL1, and around $74-81 \%$ in BF1 and GA1. However, the karateka group presents a significant higher intensity of the activation peak for RF1 and VL1 than the non-karateka group $(\mathrm{K}=52 \% ; \mathrm{NK}=24 \%, p=0.000$ and $\mathrm{K}=42 \%$; $\mathrm{NK}=27 \%, p=0.040$, respectively for $\mathrm{RF} 1$ and VL1). The EMG root mean square of all the muscles in the first activation showed a lower RMS in the agonists than in the antagonists, with a significant higher RMS for RF1 and VL1 in the karateka group $(\mathrm{K}=33 \%$; $\mathrm{NK}=16 \%, p=0.000$ and $\mathrm{K}=27 \%$; NK $=18 \%, p=0.045$, respectively for $\mathrm{RF} 1$ and VL1). In the second activation, a similar pattern was identified between groups, relatively to the sequence, where the peak of activity was reached, respectively, by the TA2, RF2 and VL2 in a time between $190 \mathrm{~ms}$ and $56 \mathrm{~ms}$, followed by the BF2 and GA2 with the peaks occurring between $56 \mathrm{~ms}$ and $38 \mathrm{~ms}$ before contact. In this second activity, the intensity of the peaks in the TA2, RF2 and VL2 muscles, increased (superior to $80 \%$ of maximum activity) and, in the antagonist BF2, the peak value decreased, but in the GA2 the peak value was maintained. Similar increases were verified in the EMG root mean square in all the muscles relatively to the first activation, except for BF2.

Table 4 shows the co-contraction time among muscles in karate and non-karate subjects, exhibiting the significant differences between groups. In the karateka group, the agonist muscles of hip flexion and knee extension tend to have a higher period of co-contraction on their first activation than in the second, but in the agonist-antagonist muscles relation in the same joint, the co-contraction time increases from the first to the second period of activity. 
In the ankle, the agonist-antagonist muscles presented a decrease in the period of cocontraction from the first activation to the second. The karateka group presented significantly smaller periods of co-contraction in the muscles of the hip and knee movements, specifically for $\mathrm{RF} 1$ - BF1 (K = $60 \mathrm{~ms}$; NK = $175 \mathrm{~ms}, p=0.044)$, VL1 - BF1 (K= $86 \mathrm{~ms}$; NK = $247 \mathrm{~ms}, p=0.006)$ and $\mathrm{RF} 2$ - BF2 (K=126 ms; NK= $159 \mathrm{~ms}, p=0.048)$, when compared to the non-karateka group.

Table 4. Average, standard deviation and significant differences between groups in the cocontraction muscles time in the execution of mae-geri by karate (K) and non-karate participants (NK).

\begin{tabular}{lcc}
\hline Co-contraction & K & NK \\
\hline RF1 - VL1 & $195 \pm 54$ & $195 \pm 101$ \\
\hline RF1 - B1F & $60 \pm 97$ a & $175 \pm 106^{\mathrm{a}}$ \\
\hline VL1 - BF1 & $86 \pm 102$ a & $247 \pm 76^{\mathrm{a}}$ \\
\hline TA1 - GA1 & $123 \pm 96$ & $128 \pm 107$ \\
\hline RF2 - VL2 & $183 \pm 44$ & $188 \pm 31$ \\
\hline RF2 - BF2 & $126 \pm 51$ a & $159 \pm 51^{\mathrm{a}}$ \\
\hline VL2 - BF2 & $151 \pm 35$ & $173 \pm 36$ \\
\hline TA2 - GA2 & $70 \pm 48$ & $81 \pm 98$ \\
\hline
\end{tabular}

Time - millisecond; RF - Rectus Femoris; VL - Vastus Lateralis; BF Biceps Femoris; TA - Tibialis Anterior; GA - Gastrocnemius. ${ }^{\text {a Indicates }}$ statistically significant differences between groups $(p \leq .05)$.

\section{4.- Discussion and conclusions}

The results showed the existence of a proximal-to-distal kinematic and neuromuscular pattern sequence in both groups. During the mae-geri execution the muscles developed two distinct periods of activity, beginning to be activated before the mechanical movement of the lower limb. As a result of the onset of muscle activity, the thigh began to move, followed by the leg and then by the foot. In the movement of those segments, the speed peak occurs more proximal to the instant of contact with the bag in the ankle, where the highest value of speed was verified, but increased progressively from the hip to the ankle. This suggests the existence of speed transference from the proximal to the distal segment during movement (Hirashima, Kadota, Sakurai, Kudo \& Ohtsuki, 2002), and that could result in an increase of speed and power in the mae-geri execution. However, the karateka group achieved a maximum speed earlier than the non-karateka group only for the proximal segment, which may be the result of the training followed by the empirical approach.

The angular speed peak of each movement finds correspondence at the time of muscle peak activity sequence, primarily in the second period of activation of the studied muscles, except for the TA, which peak occurs earlier than in the other muscles. This result might be related to the stabilization action of the ankle to prepare the foot for the impact. In the first period of muscular activation the same sequence was presented. Therefore, the two muscular activation periods began in the TA muscle, followed by the hip flexors, knee extensors and ankle plantar flexor muscles, with the antagonist $\mathrm{BF}$ being the last one to be activated.

Those double periods of muscle activation found in the execution of the mae-geri kick in the karate athletes showed the existence of a contraction-relaxation-contraction strategy. This neuromuscular control strategy may be responsible for the initial transference of body weight from the bipedal stance of support, zenkutsu dachi, on only one foot. This body weight transference, in the first instants, increases the positional angles on the lower limb segments, and was followed by the second muscular activity to do the displacement of the limb to the bag. McGill et al. (2010) found a double peak of activity in the muscles of the lower limb during a roundhouse kick performed by mixed martial arts fighters, and they concluded that the training characteristics in ballistic movements were responsible for that, giving the capacity to produce control in the muscles contraction-relaxation-contraction, increasing the performance of the kick. However, our results showed a similar double muscular activity in the subjects without karate practice, revealing that this may not be a specific training effect, but it is associated with a global neuromuscular pattern of control of this kind of skill. 
The karateka group presents a smaller positional and angular movement ranges than the non-karateka group, initiating those movements earlier, which shows a strong evidence of the training effect when associated with the task duration, being in agreement with the fact that the kinematic patterns were modified during learning and correctness of the motor tasks (Schmidt \& Lee, 2011).

For both groups, the musclar intensity of contraction shows a higher activity in the second period, in the peak and RMS, except for BF and GA, suggesting that this activity was primarily responsible for the performance of a faster and stronger kick. Between groups, the first muscle intensity activity in the RF and VL differentiates the karateka group that activated those muscles higher, which was associated with a tendency to a higher peak of velocity in the hip flexion, due to a possible increase in the ability to recruit additional motor units in the activated muscles.

In association with these notions, the smaller periods of co-contraction between RF-BF and VL1-BF1, in the karateka group, facilitate the increasing of velocity. Those parameters demonstrated the existence of an adaptation of the neuromuscular control system in the skill performance produced by training. These findings were in agreement with what was referred by Sbriccoli et al. (2010) in relation to the BF activity in the knee movement during the front kick. However, in the ankle joint, the similar time of co-contraction between groups in TA-GA muscles reflects an identical level of concern with the stabilization of the joint. Such action of the muscles should be related to the need to protect the integrity of the structure, in the preparation of the foot (as mechanical link of all segments) for the impact on the bag (Kellis \& Baltzopoulos, 1998).

For the karate practitioners in the mae-geri execution, the movement time, the positional angles and range of motion, the growing speed peak in the segmental movements of the lower limb, and changes in the muscle activity, all of that was related to an improvement of the neuromuscular activation during a complex motor skill (Liang et al. 2008; McGill et al., 2010; Quinzi et al., 2013; Sbriccoli et al., 2010).

This information could help coaches during the teaching process, to improve their workout strategies in relation to the preparation of the locomotor system, specifically in muscle training in static and dynamic stances, needed to perform ballistic movements with high quality, success and safety. Moreover, the information about the neuromuscular control and kinematic patterns was also important for researchers in further investigation related to performance.

In conclusion, general kinematic and EMG patterns were observed, being similar between karateka and non-karateka practitioners, related to the sequential events, which does not confirm initial expectations. However, as a result of training, the karateka group showed a higher EMG peak and RMS in the first activation of the knee extensor muscles, exhibiting also a better relation of the co-contraction time in the control of joint movements. These findings induce better ballistic performance in the execution of the mae-geri kick, with a faster muscle activation and lower range of motion, associated with a maximum speed of the distal segments, reached closer to the impact moment, which could report more power upon the contact.

Based on this conclusion, we may assume that karate training changes motor control strategy, promoting the improvement of performance. So, to develop the appropriate motor actions, coaches need to potentiate the acquisition, improvement and stabilization of neuromuscular and kinematic coordination patterns.

The authors suggest that, during the training process, coaches should improve their intervention in segment coordination, focusing on the improvement of the muscular strength associated with the reaction and explosive force, and directing the training to the execution of the skills to targets with real impact.

\section{References}

Ball N., \& Scurr J. C. (2011). Efficacy of current and novel electromyographic normalization methods for lower limb high-speed muscle actions. European Journal of Sport Science, 11(6):447-56.

Basmajian J. V., \& De Luca C. J. (1985). Muscles alive. Their functions revealed by electromyography. Baltimore: William \& Wilkins. 
Hermens H. J., Freriks B., Merletti R., Stegeman D., Blok J., Rau G., Disselhorst-Klug C., \& Hagg G. (2000). SENIAM 8: European recommendations for surface electromyography. Enschede: Roessingh Research and Development.

Hirashima M., Kadota H., Sakurai S., Kudo K., \& Ohtsuki T. (2002). Sequential muscle activity and its functional role in the upper extremity and trunk during overarm throwing. Journal of Sports Sciences, 20(4):301-10.

Kellis E., \& Baltzopoulos V. (1998). Muscle activation differences between eccentric and concentric isokinetic exercise. Medicine and Science in Sports and Exercise, 30:1616-23.

Konrad P. (2005). The ABC of EMG. A Practical Introduction to Kinesiological Electromyography. Version 1.0. USA: Noraxon INC.

Liang N., Yamashita T., Ni Z., Takahashi M., Murakami T., Yahagi S., \& Kasai T. (2008). Temporal modulation of agonist and antagonist muscle activities accompanying improved performance of ballistic movements. Human Movement Science, 27(1):12-28.

Link N., \& Chou L. (2011). The anatomy of martial arts, an illustrated guide to the muscles used in key kicks, strikes \& throws. Ulysses Press.

Macan J., Bundalo-Vrbanac D., \& Romic G. (2006). Effects of the new karate rules on the incidence and distribution of injuries. British Journal of Sports Medicine, 40:326-30.

McGill S. M., Chaimberg J. D., Frost D. M., \& Fenwick C. M. (2010). Evidence of a double peak in muscle activation to enhance strike speed and force: an example with elite mixed martial arts fighters. Journal of Strength and Conditioning Research, 24(2):348-57.

Micera S., Vannozzi G., Sabatini A. M., \& Dario P. (2001). Improving Detection of Muscle Activation Intervals. IEEE Engineering in Medicine and Biology, 20:38-46.

Nakazawa, A. (1999). The Shotokan karate reader for RECR 150D Beginning Shotokan karate, from Selected topics in Shotokan karate. Alaska Shotokan karate, ISKF Alaska Region.

Pappas E. (2007). Boxing, wrestling, and martial arts related injuries treated in emergency departments in the United States, 2002-2005. Journal of Sports Science and Medicine, 6:58-61.

Pieter W. (2010). Competition injury rates in young karate athletes. Science \& Sports, 25:32-38.

Pozo J., Bastien G., \& Dierick F. (2011). Execution time, kinetics, and kinematics of the mae-geri kick: comparison of national and international standard karate athletes. Journal of Sports Sciences, 29:1553-61.

Quinzi F., Camomilla V., Felici F., Di Mario A., \& Sbriccoli P. (2013). Differences in neuromuscular control between impact and no impact roundhouse kick in athletes of different skill levels. Journal of Electromyography and Kinesiology, 23(1):140-50.

Santos-Rocha, R., Veloso, A., Valamatos, M. J., Machado, M. L., \& Andre, H. I. (2009). Analysis of Kinematics of the Lower Limb during Step Exercise. Perceptual and Motor Skills, 109(3):851869.

Sbriccoli P., Camomilla V., Di Mario A., Quinzi F., Figura F., \& Felici F. (2010). Neuromuscular control adaptations in elite athletes: the case of top level karateka. European Journal of Applied Physiology, 108(6):1269-80.

Schmidt, R. A., \& Lee, T. D. (2011). Motor Control and Learning: A Behavioral Emphasis (5th ed.). USA: Human Kinetics.

Sforza C., Turci M., Grassi G., Shirai Y. F., Pizzini G., \& Ferrario V. F. (2002). The repeatability of maegeri-keage in traditional karate: a three-dimensional analysis with black-belt karateca. Perceptual and Motor Skills, 95(2):433-44.

Sørensen H., Zacho M., Simonsen E. B., Dyhre-Poulsen P., \& Klausen K. (1996). Dynamics of the martial arts front kick. Journal of Sports Sciences, 14:483-95.

VencesBrito, A. (2012). Caracterização cinesiológica do choku-tsuki executado com impacto e sua comparação com a execução sem impacto. Revista de Artes Marciales Asiáticas, 7(1): 12-25.

VencesBrito A. M., Rodrigues Ferreira M. A., Cortes N., Fernandes O. \& Pezarat-Correia P. (2011). Kinematic and electromyographic analyses of a karate punch. Journal of Electromyography and Kinesiology, 21:1023-9.

Winter, D. A. (2009). Biomechanics and motor control of human movement (4th ed.). Hoboken, N.J.: Wiley.

Zetaruk M. N., Violan M. A., Zurakowski D., \& Micheli L. J. (2005). Injuries in martial arts: a comparison of five styles. British Journal of Sports Medicine, 39:29-33. 


\section{Authors' biographical data}

António M. VencesBrito (Portugal), born in 1961, obtained the Bc degree in Radiology from the School of Technology of the Health from Lisbon, the Bc in Sport Sciences the MSc in High Performance Training and the $\mathrm{PhD}$ degree in Human Kinetics in the specialty of Motricity Sciences, from the Faculty of Human Kinetics, Technical University of Lisbon, Portugal. He is full Professor in Anatomophysiology, Applied Basic Health Sciences, coordinator and tutor of Combat Sports and Martial Arts formation in the Sports Sciences School of Rio Maior, Polytechnic Institute of Santarém, Portugal. He is researcher of the Investigation Center on Life Quality (CIQV) and collaborator in the Investigation Center of Sport, Human Health and Development (CIDESD), member of the European College of Sport Sciences and of the International Martial Arts and Combat Sports Scientific Society where he is co-responsible for the division of kinesiology. His research focuses on neural control and coordination of the muscles activity and in sport physiology. Within these areas, he has authored and co-authored several papers in peer-reviewed journals and in conference papers/abstracts. He is Shotokan karate practitioner since 1975 and is teacher on coach education of the National Karate Federation - Portugal, trainer of the Sportive Association - Portuguese Center of Karate and the Karate Association of the Setubal District. He is member of the Idokan Poland Association - Karate division. E-mail: abrito@esdrm.ipsantarem.pt.

Marco A. Colaço Branco (Portugal), born in 1978, obtained the Bc degree in Sport Sciences at the Sport Sciences School of Rio Maior, Polytechnic Institute of Santarém in 2002, the MSc in Sport Sciences in 2010, and is a PhD candidate in Human Kinetics, in the Faculty of Human Kinetics, University of Lisbon, Portugal. He is an assistant professor of Biomechanics, Motor Control and Learning, and tutor of Combat Sports and Martial Arts formation in the Sports Sciences School of Rio Maior, Polytechnic Institute of Santarém, Portugal. He is researcher as graduated student of the Interdisciplinary Centre for the Study of Human Performance, Faculty of Human Kinetics, University of Lisbon, Portugal. His research focuses exercise and health in special populations and in sport performance. He is practitioner of Wado-Ryu karate since 1996 and is a coach at the Wado-Kai Karate Association in the district of Santarém. E-mail: marcobranco@esdrm.ipsantarem.pt.

Renato M. Cordeiro Fernandes (Portugal), born in 1976, got the Bc degree in Sports Science from the Faculty of Human Kinetics, Technical University of Lisbon in1999 and a Master's degree in Training the Young Athlete by the Faculty of Human Kinetics, Technical University of Lisbon2006. He is currently a PhD student in Sport Sciences at the University of Trás-os-Montes and Alto Douro. Currently is a teacher at Sports Sciences School of Rio Maior, Polytechnic Institute of Santarém, Portugal, where he teaches Anatomophysiology and Traumatology and First Aid. Research topics: pediatric exercise and sport physiology, sports medicine and neuromuscular function. E-mail: rfernandes@esdrm.ipsantarem.pt.

Mário A. Rodrigues Ferreira (Portugal), born in 1984. He obtained the Bachelor degree in Sport at the Sport Sciences School of Rio Maior, Polytechnic Institute of Santarém in 2007, and the Bachelor degree in Physical Education at the Faculty of Sport Sciences and Physical Education of the University of Coimbra in 2009. He is currently a PhD student in Sport Sciences at the University of Madeira and Sport Sciences School of Rio Maior, Polytechnic Institute of Santarém. He is member of the European College of Sport Sciences since 2008. His main research interests are motor control and learning, neuromuscular activation in sport-specific motor skills, exercise and sport physiology, training and testing. E.mail: marioaf@gmail.com.

Orlando J. S. M. Fernandes (Portugal), born in 1962 . Is graduated in Sports Science - Master in Sport Science, PhD in Sport Science. Currently is Assistant Professor of the University of Évora where teaches Biomechanics and Movement Analysis. Research topics: Sports Biomechanics, Motor Control and neuromuscular function. fernandes.orlando@gmail.com.

Abel A. Abreu Figueiredo (Portugal), born in 1964. He has a Ph.D. in Sport Sciences, a MSc in Physical Education and a BSc in Physical Education - Sports Branch. He is Adjunct Professor on the Sport Sciences and Motricity Department of the Polytechnic Institute of Viseu (Portugal) - School of Education, where he is the coordinator of the Sport and Physical Activity BSc course (1 $1^{\text {st }}$ cicle), and very linked with Sport Coaching Education programs in Higher Education and Federations with special relevance for Martial Arts and Combat Sports. His teaching domains are Sport Pedagogy, Sport Methodology of Training, and Martial Arts and Combat Sports. He is researcher on the "Centro de Estudos em Educação, Tecnologia e Saúde" (CI\&DETS). He is Vice-President of IMACSSS - International Martial Arts and Combat Sports Scientific Society and linked with Karate as Technical Adviser of National Karate Federation - Portugal, and President of National Karate Coach Association - Portugal. He is a Karate Coach, and a Black Belt $6^{\text {th }}$ dan in Goju-Ryu Karatedo. E-mail: abel.figueiredo@esev.ipv.pt.

Gonçalo Branco (Portugal), born in 1990. He has a Bc degree in Sports Science by the Faculty of Human Kinetics, Technical University of Lisbon, where he is currently a MSc in High Performance Training student.

He is a karate practitioner since 2006, and a coach of the Wado-Kai Karate Association in the district of Santarém. E-mail: gacb@sapo.pt. 